\title{
Gestão estratégica da qualidade para empresas produtoras de alimentos orgânicos: diretrizes para a expansão do mercado consumidor
}

\begin{abstract}
RESUMO
O presente estudo propõe uma orientação específica para empresas produtoras de alimentos orgânicos com foco na gestão estratégica da qualidade. Para tal, utiliza, como base, dados de uma análise exploratória dos benefícios (internos e externos) que empresas brasileiras produtoras de alimentos orgânicos certificadas podem dispor. Para tanto, emprega uma pesquisa do tipo survey. A conclusão primeira do presente trabalho é que a certificação é útil e relevante para as empresas produtoras de alimentos orgânicos. Mas parece não ser suficiente para definir, para tais empresas, um projeto estratégico de atuação consistente no mercado. É possível que isso decorra do fato de que o modelo de certificação, em geral, prioriza a Qualidade de Conformação, sem atentar, com mais cuidado, para a Qualidade de Projeto. Assim, a proposta prática é a priorização das relações das empresas produtoras de alimentos orgânicos com as faixas de mercado às quais pretendem atender. A proposta deve considerar, obviamente, características relevantes do setor.
\end{abstract}

Palavras-chave: Gestão estratégica da qualidade. Alimentos orgânicos. Mercado. Consumo.

Cristiane Alves Anacleto cristianeanacleto@yahoo.com.br 


\section{INTRODUÇÃO}

O setor de produção de alimentos é crítico em qualquer parte do planeta por sua posição estratégica nos modelos de elaboração de planejamento governamental e de estruturação de políticas públicas. Ao mesmo tempo, os produtos alimentícios subordinam-se às leis de mercado como qualquer outro bem de consumo. Assim, por exemplo, sofrem os efeitos de crises econômicas; dependem das leis de oferta e demanda; sujeitam-se às alterações de hábitos, preferências e expectativas dos consumidores; subordinam-se às novas percepções de usuários de bens ou serviços e, também, sofrem com o alcance de níveis de saturação de faixas específicas de mercado.

Como regra geral, para fazer frente às alterações dos padrões de consumo, as organizações produtivas têm buscado criar vantagens competitivas sustentáveis por meio da diferenciação dos produtos de acordo com as novas exigências dos consumidores, ou seja, lançando mão de estratégias inovadoras. Inseridos no contexto usual do mercado de consumo, os produtos alimentícios, assim, tendem a utilizar a mesma trilha para assumir posições estratégicas.

Além das questões sociais e mercadológicas, duas outras dimensões devem ser consideradas. Inicialmente, há de se considerar o viés ambiental e o do desenvolvimento sustentável na produção de alimentos, componentes que enfatizam discussões de governos e da sociedade nos últimos tempos, considerados essenciais na elaboração de qualquer agenda que inclua o setor produtivo. Ambos os aspectos têm forte apelo com os consumidores. Igualmente tem sido considerada relevante a preocupação com o bem-estar físico e, mais em geral, com a preservação da saúde. Assim, a demanda por produtos considerados saudáveis tem crescido em todo o mundo.

Os alimentos orgânicos fazem parte de um grupo de produtos que se inclui nas quatro seguintes situações. Inserem-se no esforço governamental de suprir suas áreas de atuação com níveis adequados de atendimento às necessidades básicas da população; são regulados por leis usuais de mercado; atendem a prescrições de preservação ambiental e são considerados saudáveis.

A qualidade dos produtos orgânicos no Brasil é garantida de três diferentes maneiras: com a certificação, com o controle social para venda direta sem certificação e com os sistemas participativos de garantia. Juntos, esses três modelos formam o Sistema Brasileiro de Avaliação da Conformidade Orgânica (SisOrg). Lin, Zhou e Ma (2010) afirmam que a certificação agregada à produção de alimentos orgânicos confere maior qualidade ao produto final. No entanto, Pearson, Henryks e Jones (2011) asseveram que as diretrizes que orientam as empresas produtoras de alimentos orgânicos rumo à adequação de seus produtos ao seu mercado consumidor são ainda pouco exploradas. Portanto, identificou-se, no referencial teórico consultado, que estudos com foco na gestão estratégica da qualidade para as empresas do setor em estudo ainda não são o foco principal de pesquisas da comunidade científica.

Assim, esta pesquisa propõe uma orientação específica para empresas produtoras de alimentos orgânicos com foco na gestão estratégica da qualidade. Para tal, utiliza, como base, dados de uma análise exploratória dos benefícios (internos e externos) que empresas brasileiras produtoras de alimentos orgânicos certificadas podem dispor.

\section{REFERENCIAL TEÓRICO}

Nesta seção, são apresentados os principais conceitos que embasaram a construção do modelo. Primeiramente, discute-se a evolução dos alimentos orgânicos no mercado; em seguida, seu conceito e o seu significado para os consumidores. E, por último, toda a dinâmica da certificação de alimentos orgânicos no Brasil é apresentada.

\subsection{Alimentos orgânicos}

A dinâmica do mercado mundial, com o lançamento de novos produtos que atendam a novas demandas, também atinge o setor de alimentos. O desenvolvimento de novos produtos no segmento alimentar vem sofrendo influência do crescente interesse por alimentos que atendam às necessidades emergentes dos consumidores, como é o caso da preocupação com sua própria saúde e com a preservação ambiental (CHEN, 2009). Uma das tendências no ramo alimentício hoje é a produção de alimentos orgânicos, fato evidenciado pelos números que indicam que a demanda por esses produtos tem crescido entre os consumidores nos últimos anos (CICEK; KARTALKANAT, 2010; CRINNION, 2010; LIN; ZHOU; MA, 2010).

$\mathrm{Na}$ década passada, o alimento orgânico representava apenas um pequeno segmento do mercado. Nele, um reduzido número de consumidores estava disposto a pagar preços maiores por tais produtos, já que acreditava estar consumindo um alimento com maior qualidade, mais saudável e que dispunha de maior confiabilidade em termos do processo produtivo (PELLEGRINI; FARINELLO, 2009). Assim, produzir alimentos orgânicos foi uma tendência da indústria alimentícia inicialmente circunscrita a algumas regiões do planeta, que refletia, sobretudo, a oposição ao consumo de alimentos industrializados (GUTHMAN, 2003; LIN; ZHOU; MA, 2010). 
Nos anos seguintes, a maior aceitação dos alimentos orgânicos foi impulsionada pela ampla aceitação de suas características de qualidade, o que fez crescer de forma significativa o número de consumidores, e, por consequência, de varejistas ou de processadores (ROSIN; CAMPBELL, 2009).

Conceitualmente, alimento orgânico é aquele produzido em conformidade com as normas determinadas para a sua produção, o seu manuseio, os seus estágios de processamento e a sua comercialização. O produto deve ser devidamente certificado por um organismo ou autoridade específica para esse fim (RAMESH; SINGH; SUBBA RAO, 2005). Como regra geral, a definição do alimento orgânico é baseada no seu processo de produção (ANDERSON; WACHENHEIM; LESCH, 2006).

Alguns autores, entretanto, salientam que o tema orgânico é um marco de rotulagem (KOUBA, 2002; RAMESH; SINGH; SUBBA RAO, 2005), o que não parece ser totalmente correto. Deve ficar claro, para o consumidor, que "orgânico" não está relacionado com alimento seguro (MAGKOS; ARVANITI; ZAMPELAS, 2006). O rótulo "orgânico" oferece a garantia aos consumidores de que nenhum ingrediente do alimento tenha sido objeto de irradiaçã̃o e que organismos geneticamente modificados são excluídos da sua produção (KOUBA, 2002).

Os alimentos orgânicos diferem-se quanto à variedade e à origem (SIDERER; MAQUET; ANKLAM, 2005). Além disso, são produtos que têm a durabilidade reduzida em relação aos alimentos convencionais (CAMPBELL, 2007). A proposta da produção de alimentos orgânicos é combater os impactos ambientais e sociais da produção de alimentos, além de promover melhor qualidade de vida às pessoas que os consomem (PUSSEMIER et al., 2006).

Apesar da projeção de alto crescimento no consumo de produtos orgânicos, as características do consumidor que contribuem para esse aumento não são bem compreendidas (ZHANG et al., 2008). Entender o comportamento dos consumidores em relação aos alimentos orgânicos pode ajudar aos produtores a compreender os valores de consumo e, por sua vez, desenvolver um modo de produção e uma abordagem de marketing adequados a tais valores, além de investir em novos produtos, melhorar os existentes e, de maneira mais ampla, formular as diretrizes da gestão da qualidade das suas empresas (CHANG; ZEPEDA, 2005; BERLIN et al., 2009).

Na literatura analisada como suporte ao presente trabalho, observa-se que há um consenso geral em termos das razões que determinam a preferência dos consumidores pelos alimentos orgânicos em relação a alimentos convencionais similares. Constata-se, por exemplo, que há diferenças entre a atitude dos consumidores - em geral, positiva - para com o alimento orgânico e o nível relativamente baixo - de compras efetivas.

Mas, em geral, pode-se comprovar que o produto orgânico possui diferenciação no mercado em vista de suas características intangíveis. Essas características têm determinado grande consumo e rápido crescimento dos referidos produtos no mercado. No entanto, deve-se ressaltar que há divergência entre a percepção dos consumidores de que esses alimentos são benéficos à saúde e as evidências científicas de que, de fato, o são. Em outros termos, não há clara resposta para a pergunta: os alimentos orgânicos são mais saudáveis ou não? (PEARSON; HENRYKS; JONES, 2011). Não há como deixar de evidenciar o fato de que os consumidores parecem pensar que sim, conforme apontam pesquisas práticas, como a de Gibbon, Lin e Jones (2009).

\subsection{Certificação de alimentos orgânicos}

Por razões compreensíveis, as empresas que produzem alimentos orgânicos têm o desafio de garantir os atributos de qualidade e de segurança exigidos pelo consumo de alimentos.

Por suas características próprias, contudo, os alimentos orgânicos dispõem de apelo próprio de mercado. Assim, se os padrões de qualidade forem conhecidos pelos consumidores, o produto passa a adquirir um valor específico, que pode determinar, por exemplo, que os consumidores se disponham a pagar, por eles, um preço mais elevado que o dos concorrentes.

Padrões de qualidade consistentes implicam maior Qualidade de Conformação, um conceito bem conhecido no âmbito da Gestão da Qualidade (PALADINI, 2010). Como decorrência de uma norma usual de mercado, a maior conformidade do produto ao mercado para o qual ele se destina está associada com o aumento das vendas.

Um dos meios essenciais para garantir a qualidade da produção dos alimentos orgânicos é o processo de certificação, que tem sido uma prática consagrada e que se aplica, igualmente, ao modelo de produção aqui estudado.

Observa-se, entretanto, que a regulação da produção orgânica, bem como o seu processamento, utiliza conceitos de qualidade relacionados ao processo produtivo e, com essa ênfase, nem sempre são priorizados modelos de gestão da qualidade orientados aos atributos do produto exigidos pelo consumidor. Dessa forma, torna-se necessário alinhar o processo de certificação orgânica às exigências dos consumidores.

O surgimento das primeiras normas para a produção orgânica centrou foco na certificação dos produtores de alimentos orgânicos. Com esse viés, existem cerca de cem diferentes normas para a produção de alimentos orgânicos em todo o mundo. Por existirem várias certificadoras, em diferentes países, os governos introduziram regulamentos relativos à certificação e rotulagem. 
No Brasil, a agricultura orgânica começou a ser regida pela Lei no 10.831 , promulgada em 23 de dezembro de 2003. É um marco histórico para a agricultura orgânica brasileira, pois, até aquele momento, o setor produtivo orgânico era orientado somente por normas e diretrizes internacionais.

Todos os produtores certificados como orgânicos no Brasil, bem como as organizações certificadoras que atuam no setor no país, devem trabalhar de acordo com o Decreto n॰ 6.323 , de 27 de dezembro de 2007, que regulamenta a Lei $n^{\circ} 10.831$, de 23 de dezembro de 2003. Os segmentos envolvidos na rede de produção orgânica tiveram até 31 de dezembro de 2010 para se adequarem às regras estabelecidas na legislação então em vigor e no Decreto $n^{\circ} 7.048$, além de nos demais atos complementares.

O Decreto $n^{\circ} 6.323$, em particular, apresenta as disposições que devem ser consideradas para a elaboração e a melhoria da gestão da qualidade para a produção de alimentos orgânicos. A legislação brasileira apresenta mecanismos de controle e informação da qualidade orgânica, dispostos pela Instrução Normativa no 19 , de 28 de maio de 2009 . Um aspecto que deve ser ressaltado nessa instrução normativa é o procedimento identificado pelo Ministério da Agricultura, Pecuária e Abastecimento (MAPA) para comunicar a qualidade ao consumidor. Assim, segundo esse órgão, a informação da qualidade orgânica nos rótulos é realizada pela utilização na parte frontal do produto de um dos termos: "orgânico", "produto orgânico", "produto com ingredientes orgânicos" (MAPA, 2010).

A finalidade primeira da certificação éfornecer aos consumidores a segurança que os produtos que compram são realmente produzidos organicamente. Ao mesmo tempo, a certificação é um requisito processual utilizado para identificar os produtos orgânicos que cumprem as normas de importação aplicáveis ao setor. O comércio de produtos orgânicos no Brasil é regido pela obrigatoriedade da certificação orgânica dos itens comercializados, exceto para os agricultores familiares que vendem os seus produtos diretamente aos consumidores finais. Até o final de 2013, oito organizações eram credenciadas pelo MAPA.

O processo de certificação inicia-se quando os produtores buscam as informações necessárias para o desenvolvimento do processo nas agências certificadoras. De posse dessas informações, os produtores atendem ao que foi requisitado em documentos próprios e, na sequência, assinam um contrato de certificação. Segue-se, então, o processo de visita da agência certificadora ao produtor. O relatório decorrente dessa visita é avaliado por um comitê específico da agência certificadora, que pode, com base nesse relatório, emitir a certificação. Relatórios periódicos anuais do produtor certificado são exigidos pela agência certificadora.

Deve-se observar que referido procedimento é o adotado na maioria dos países que investem na certificação de produtos agrícolas. Além da inspeção inicial para obter o certificado orgânico, o processo de certificação envolve inspeções anuais. Nessas avaliações, os inspetores verificam se o processo produtivo e as práticas a ele associadas estão em conformidade com os padrões orgânicos. Produtos certificados podem entrar na cadeia comercial com situação destacada (TRANTER et al., 2009).

Como mencionado, o comércio de produtos orgânicos no Brasil é regido pela obrigatoriedade da certificação orgânica dos itens comercializados, exceto para os agricultores familiares que vendem os seus produtos diretamente aos consumidores finais. Em novembro de 2009, o Ministério da Agricultura e Pecuária do Brasil instituiu o selo único oficial do sistema brasileiro de avaliação da conformidade orgânica. Entretanto, somente as modalidades de Certificação por Auditoria e Sistemas Participativos de Garantia autorizam o uso do selo do Sistema Brasileiro de Avaliação da Conformidade Orgânica (SisOrg) (MAPA, 2010).

No caso de contração da Certificadora por Auditoria, o produtor receberá visitas de inspeção inicial e periódicas e manterá obrigações perante o MAPA e a certificadora, com custo a ser estabelecido em contrato. Se o produtor descumprir as normas, a certificadora retira seu certificado e informa ao MAPA. Os Sistemas Participativos de Garantia (SPG) são grupos formados por produtores, consumidores, técnicos e pesquisadores que se autocertificam, ou seja, estabelecem procedimentos de verificação das normas de produção orgânica daqueles produtores que compõem o SPG. Precisam ser credenciados no Ministério da Agricultura, Pecuária e Abastecimento, que fiscaliza seu trabalho. Os produtos do SPG recebem o selo brasileiro.

\section{MÉTODO DE PESQUISA}

Diante da lacuna identificada no referencial teórico consultado, o método de pesquisa utilizado conduziu à construção das diretrizes que compõem o modelo gerencial da qualidade para as empresas produtoras de alimentos orgânicos. As empresas do citado setor podem utilizar o modelo para orientar-se ao seu mercado consumidor.

Do ponto de vista da natureza de pesquisa, classifica-se esta pesquisa como aplicada. Segundo Marconi e Lakatos (2001), este tipo de estudo gera conhecimentos para aplicação prática, dirigidos à solução de problemas específicos. O objetivo descritivo deste trabalho envolve a análise de algumas características das empresas produtoras de alimentos orgânicos do Brasil. Para tal, utiliza-se do levantamento tipo survey, segundo as classificações para procedimentos técnicos de Gil (2002). 
Baseado nas informações fornecidas pelos endereços eletrônicos de três certificadoras credenciadas pelo MAPA - Instituto de Tecnologia do Paraná (TECPAR); IBD Certificações e ECOCERT Brasil -, foi possível determinar a quantidade de empresas que possuem certificação orgânica no Brasil. Espalhadas por diversos estados brasileiros, aproximadamente seiscentas empresas possuíam projetos orgânicos validados por essas certificadoras, até o fim do primeiro semestre de 2012.

Como na maioria das pesquisas científicas é praticamente impossível avaliar todos os elementos que compõem uma população de interesse de estudo, procedeu-se o cálculo da amostra a ser investigada. Assim, considerando o erro amostral tolerável de 5\%, calculou-se o tamanho da amostra em 201. A amostra final foi formada por meio do sorteio das empresas de uma população composta por seiscentas organizações, ou seja, amostragem aleatória simples.

Como instrumento de coleta de dados, optou-se por um questionário estruturado, com a possibilidade de envio, acesso, preenchimento e devolução on-line. A plataforma Google Docs foi utilizada para a sua construção. Essa ferramenta disponibiliza a opção de envio automático para os respondentes via correio eletrônico, além de permitir o preenchimento das respostas automaticamente, armazenando os dados em um arquivo digital.

O envio de questionário por e-mail é utilizado por outras pesquisas que estudam alguma característica do consumidor relativamente a algum produto específico. Os trabalhos de Powell et al. (2011) e de Webster et al. (2010) também utilizaram questionários enviados por e-mail. Segundo Baruch e Holtom (2008), os questionários eletrônicos apresentam taxas de resposta aparentemente mais elevadas, custos menores de envio e retorno, além de tempos menores de preenchimento do que os aplicados por meio físico. Além disso, possibilitam o envio do mesmo e-mail para vários endereços de uma só vez, permitem maior controle dos questionários enviados, garantem maior abrangếncia territorial e asseguram o sigilo e a privacidade aos respondentes.

Surveys baseadas em consultas eletrônicas têm se tornado mais populares, pois são consideradas mais rápidas, melhores, mais baratas e mais fáceis de serem conduzidas do que os meios tradicionais de questionários (EVANS; MATHUR, 2005; SCHONLAU; FRICKER; ELLIOTT, 2001).

O questionário foi dividido em duas partes, totalizando dez questões. A primeira parte consiste da caracterização das empresas. As três primeiras perguntas em formato de texto tinham como objetivo levantar as seguintes informações: estado brasileiro onde a empresa está localizada; ano de obtenção da certificação orgânica; número de funcionários. Os produtos comercializados pelas empresas e o seu mercado consumidor também foram investigados nessa primeira parte, por meio de uma pergunta em formato de seleção.

$\mathrm{Na}$ segunda parte, as informações sobre a expansão do mercado relacionado à certificação e aos benefícios operacionais oriundos da certificação foram apresentadas em formato de caixas de seleção. E, por fim, três perguntas em formato de múltipla escolha com as seguintes informações foram apresentadas: se as empresas treinavam sua mão de obra sobre o modo de produção orgânico, se a empresa possuía outro tipo de certificação e se as vendas aumentaram em relação ao ano de 2010.

Conforme Aaker et al. (2001), ao fim da elaboração do questionário, sugere-se que se faça um pré-teste, cujo objetivo é assegurar ao pesquisador que o questionário atinge às suas expectativas de captação das informações necessárias. O pré-teste deve começar com o próprio pesquisador, preenchendo seu próprio questionário, e, posteriormente, com uma pequena amostra selecionada. Devem ser observados no pré-teste alguns pontos relevantes, como sentido da pergunta, dificuldade em responder, interesse e atenção do respondente, fluxo do questionário e padrões de não preenchimento. Assim, dez empresas foram selecionadas pelo critério de acessibilidade para fazerem o pré-teste do questionário. Após a obtenção das respostas, as correções necessárias foram feitas e o questionário enviado para a amostra de empresas que compõe o estudo.

O período considerado para recebimento de respostas estendeu-se por dois meses. Para garantir a representatividade da amostra, os questionários foram enviados em dias diferentes para as empresas das várias regiões do Brasil. Posteriormente a esse período, um total de sessenta questionários preenchidos retornou à plataforma Google Docs. A taxa de resposta foi de $29,85 \%$. Segundo Ruiz de Maya, López-López e Munuera (2011), uma taxa de resposta de 10\% a 15\% pode ser considerada para a análise dos resultados. Após o retorno dos questionários, procedeu-se à análise dos dados por meio de estatística descritiva. A abordagem quantitativa predomina nessa etapa da pesquisa. Os dados obtidos das respostas foram expressos em percentuais.

\section{DESCRIÇÃO E ANÁLISE QUANTITATIVA DA PESQUISA}

A maior parte das empresas consultadas está situada no Sudeste e no Sul do Brasil, regiões de maior densidade populacional. Mais da metade dos entrevistados (58\%) afirmaram adotar a agricultura orgânica como uma estratégia para a diversificação do negócio convencional. Isso confirma a declaração de Yakovleva e Flynn (2009) de que os agentes das cadeias de produção de alimentos convencionais adotam a produção orgânica como parte de sua estratégia de diversificação, uma vez que esse sistema possui um alto potencial de nicho de inovações, podendo transformar o 
sistema tradicional alimentar.

As vendas das empresas pesquisadas concentram-se no mercado brasileiro. 54\% das empresas têm o Brasil como principal consumidor. Isso se deve ao fato de as cadeias locais de produção predominarem no setor de alimentos orgânicos, como afirmam Cicek e Kartalkanat (2010). Os autores ainda ressaltam que essa tendência é uma estratégia adotada pelos agentes da cadeia para alavancar o consumo sustentável. As cadeias mais curtas e locais diminuem a pressão pela qualidade, já que é mais fácil identificar e monitorar as variáveis que interferem diretamente sobre elas, mas isso não significa diminuir os níveis da qualidade. Dezenove por cento das empresas têm como maior mercado a União Europeia, enquanto $17 \%$ têm como principal público consumidor os Estados Unidos, 6\% concentram suas vendas para o Japão e 4\% para outros mercados.

As frutas predominam como o produto mais comercializado pelas empresas pesquisadas (24\%), pois no Brasil, em virtude de seu extenso território e posição geográfica, produzem-se frutas tropicais e também as de clima temperado, estas produzidas no Sul do país. As frutas de clima temperado, tendo em vista a necessidade de adaptação ao clima brasileiro, são bem mais perseguidas por pragas e doenças, exigindo, desse modo, trato cultural adequado. A segunda opção mais selecionada pelos respondentes (empresas) foi "Outros", no qual se destaca o chá orgânico (16\%). Em seguida, os demais produtos apontados pelos respondentes em ordem decrescente foram: processados (14\%), legumes (12\%), hortaliças (11\%), cereais (6\%), bebidas (6\%), mel (4\%), leite (2\%) e carnes (1\%).

$\mathrm{Na}$ análise do ano de obtenção da certificação, o resultado mostrou que até 2000 dezesseis empresas obtiveram a certificação e, desse ano, até 2010, 45 empresas. O ano de 2010 é o que apresenta maior número de obtenção de certificação orgânica - oito empresas foram certificadas. Isso se deve ao crescimento à demanda por esses produtos, além da promoção crescente em meios de comunicação. Tal constatação igualmente é confirmada em referências bibliográficas consultadas (CICEK; KARTẢLKANAT, 2010; CRINNION, 2010; LIN; ZHOU; MA, 2010).

O Instituto Brasileiro de Geografia e Estatística (IBGE) classifica as empresas quanto ao número de empregados. Segundo o número de empregados, as empresas são classificadas em: - micro (1 a 19 empregados); - pequena (20 a 99 empregados); - média (100 a 499); - grande (mais de 500 empregados). A maior parte das empresas consultadas (51\%) enquadra-se na classificação de microempresa, 29\% são pequenas empresas, 10\% grandes e 10\% médias empresas (IBGE, 2010). Segundo o MAPA, a agricultura orgânica costuma ser relacionada a produções em pequena escala. Porém, desde a década de 1970, quando o processo orgânico começou a ser difundido no meio acadêmico e científico, novas tecnologias foram desenvolvidas e estudos realizados para possibilitar produções em grande escala e evitar pragas e doenças sem a utilização de agrotóxicos. Esse processo evolutivo pode ser observado em culturas como a do café, cana-de-açúcar e morango.

Para as empresas respondentes, o principal benefício operacional oriundo da certificação orgânica é a maior organização interna da empresa (41\%). Essa organização vem da padronização das atividades internas relativa à venda da produção. Esse fato também é confirmado pela literatura técnica da área. De acordo com Raynolds (2004), por exemplo, a certificação orgânica tende a exercer papel fundamental para a governança da rede, moldando as especificações do produto, os parâmetros de produção e a participação das empresas no processo. Em seguida, o segundo benefício mais destacado pelas empresas foi o maior controle dos insumos utilizados no processo produtivo, já que a certificação procura garantir um sistema agropecuário sustentável (27\%).

Dois conceitos são fundamentais na produção orgânica: a relação de confiança entre produtor e consumidor, e o controle de qualidade. Assim, o terceiro benefício apontado como oriundo da certificação é o estabelecimento de um padrão mínimo de qualidade (17\%). O quarto benefício (9\%) vem complementar a comprovação de que os dois conceitos da agricultura orgânica são colocados em prática: a certificação permite o estabelecimento de pontos de controle na produção. $\mathrm{O}$ quinto benefício apontado pelos respondentes é a padronização de processos (6\%).

Em relação ao mercado, a maior parte das empresas afirmou que a certificação orgânica permitiu expandir a parcela de mercado. Além disso, muitos afirmaram que a certificação permite melhorar a imagem da empresa no mercado e aumentar a satisfação dos seus consumidores. Consequentemente, o aumento das vendas foi constatado, pois, além de garantir a exportação dos produtos, os pontos de comercialização puderam ser aumentados. $O$ último benefício assinalado pelos respondentes foi a superação da concorrência por meio da certificação.

Outra questão considerada refere-se à formação dos recursos humanos. Sobre tal aspecto, as empresas foram questionadas a respeito do fato de treinarem ou não os seus funcionários quanto ao modo de produção orgânico. A maior parte da amostra consultada, 53 empresas, cerca de $80 \%$, treina os funcionários de acordo com as normas da certificadora que emitiu seus certificados de produção orgânica.

Outro ponto relevante da pesquisa refere-se ao fato de que as empresas inseridas na amostra possuíam outro tipo de certificação relacionada a alimentos e a sistemas de gestão da qualidade. Da amostra total, 55\% das empresas possuíam além da certificação orgânica outro tipo de certificado. 


\section{UM MODELO GERENCIAL DA QUALIDADE PARA AS EMPRESAS PRODUTORAS DE ALIMENTOS ORGÂNICOS}

Tendo em vista as análises desenvolvidas no item anterior, propõe-se aqui, de forma objetiva e sistemática, um modelo gerencial para as empresas produtoras de alimentos orgânicos. O modelo compõe-se de seis partes, que envolvem a percepção do modelo; a abordagem conceitual da qualidade e os referenciais de atuação do modelo, além das ações que compõem os três ambientes de gestão (operacional, tático e estratégico).

\subsection{Percepção do modelo}

O processo de certificação prioriza a Qualidade de Conformação do processo produtivo das empresas produtoras de alimentos orgânicos. Esse viés traz inegáveis ganhos para as empresas, mas não define, por si só, um direcionamento claramente caracterizado para o pleno atendimento do mercado atual, para a definição de novas faixas de mercado a atender, nem detecta tendências que possam determinar ações futuras da organização. Assim, propõe-se que o conceito de Qualidade de Projeto seja considerado como foco do presente modelo já que, para ser comercializado em âmbito nacional, todo alimento orgânico deve ser certificado por alguma certificadora credenciada pelo MAPA. Os conceitos de Qualidade de Conformação e Qualidade de Projeto são amplamente discutidos na literatura técnica da Gestão da Qualidade (PALADINI, 2010).

A produção e a comercialização dos alimentos orgânicos são regulamentadas pelos requisitos da legislação brasileira para a produção orgânica. As certificadoras estabelecem um padrão de qualidade dos alimentos orgânicos. Os requisitos de produção são determinados com base em diretrizes para alcançar referido padrão. Assim, para o órgão público e para as certificadoras, a qualidade dos alimentos orgânicos centra-se na capacidade da produção em atender aos requisitos por eles determinados, Qualidade de Projeto. Nesse caso, a gestão da qualidade tem, portanto, foco no processo produtivo dos alimentos.

Assim sendo, a obtenção da certificação orgânica emitida por uma das agências credenciadas pelo governo federal é um item estratégico para o posicionamento no mercado das empresas do setor.

O fato de as empresas pesquisadas portarem mais de uma certificação requer, também, que seja definido um modelo de integração de normas. Para a chamada prática da integração dos modelos de certificação, ou seja, a construção de um Sistema Integrado de Gestão (SIG), utilizaram-se, como referência, trabalhos de De Cicco (2000), Idrogo et al. (2008), Campos (2006), Arvanitoyannis, Krystallis e Kapirti (2003) e Marshall e Standifird (2005), que propõem determinados procedimentos e apontam benefícios obtidos na implantação do SIG, fragilidades ao longo da implantação do processo e ações práticas usuais para maximizar os primeiros e minimizar os segundos.

\subsection{Abordagem conceitual da qualidade}

A certificação investe prioritariamente na gestão da qualidade do processo. Vários autores consideram abordagens conceituais da qualidade baseadas no processo, enfatizando tanto a Qualidade de Conformação quanto mecanismos de gestão voltados para a eficiência das operações produtivas e o atendimento às especificações de projeto. É o caso das seguintes definições:

- Qualidade é o grau específico em que um produto específico conforma-se a um projeto ou a uma especificação (GILMORE, 1974).

- Qualidade é a característica que faz com que um produto seja projetado e fabricado para executar apropriadamente a função designada (ROTHERY, 1993).

- Qualidade é um conceito no qual se concretiza o esforço para atender a padrões usualmente aceitos, como aqueles definidos por organismos de normalização ou credenciamento, tendo como foco o processo em andamento na organização ou o programa que foi estabelecido, considerandose, sempre, objetivos e missão da própria organização (VLÃSCEANU; GRÜNBERG; PÂRLEA, 2009).

Prioriza-se a abordagem conceitual de Vlãsceanu, Grünberg e Pârlea (2009) no presente modelo, já que a meta é estruturar um processo interativo (organização - mercado) de Qualidade de Projeto.

Os alimentos orgânicos, contudo, têm sua imagem fortemente associada à qualidade de vida. Isso implica uma relação direta com questões ambientais, sustentabilidade, e, mais em geral, com o chamado impacto social da qualidade.

Dessa forma, uma terceira abordagem deve ser contemplada no modelo. Em termos conceituais, utiliza-se aqui o referencial de Taguchi (1990), segundo o qual, a qualidade de um produto é determinada pela medição das perdas econômicas que seu uso acarreta a toda a sociedade, desde o instante em que ele é colocado à venda. Assim, não basta um produto atender ao que dele requer quem o vai consumir ou utilizar. É fundamental que o produto não produza danos à sociedade de modo geral, que pode ser prejudicada se o produto agride o meio ambiente, gera riscos à integridade física, ou até mesmo, à vida das pessoas, enfim, cria algum tipo de danos a terceiros. Além de mais 
ampla que as demais, tal abordagem é totalmente compatível com a imagem que está associada ao produto "alimento orgânico".

Por fim, agregando as três abordagens, o modelo requer ações com ênfases específicas. Para tanto, lançou-se mão do bem conhecido conjunto de dimensões conceituais da qualidade de David Garvin. Em seu trabalho pioneiro de 1984 (GARVIN, 1984), o autor estabeleceu cinco enfoques conceituais para a qualidade. Tais enfoques definirão os referenciais de atuação do modelo, descritos a seguir.

\subsection{Referenciais de atuação do modelo}

De acordo com o trabalho de Garvin (1984), há cinco referenciais básicos que podem ser definidos como focos da Gestão da Qualidade. Em se tratando de produtos orgânicos, tais referenciais podem ser descritos como segue:

a) Abordagem transcendental: Esta abordagem investe na imagem e na marca de produtos e de organizações produtivas. Por este referencial, deve ser ação básica das organizações que atuam no setor de alimentos orgânicos valorizar as características dos produtos, associando-os a um tipo de alimentação diferenciada. Algumas ações baseadas nesta abordagem são as seguintes:

- Atuar mais na promoção do setor por meio de cursos e campanhas de informação, função da administração pública.

- Não destacar afirmações relacionadas à saúde porque não existe um consenso na literatura dos seus benefícios nas campanhas públicas de promoção dos alimentos orgânicos.

- Criar estratégias de marketing pelos órgãos governamentais para a criação de um ambiente que facilite o desenvolvimento do mercado de orgânicos.

- Desenvolver estratégias de marketing direcionadas aos consumidores que estão dispostos a pagar extra pelos alimentos orgânicos.

- Promover diversos canais de comercialização.

- Usar técnicas padrões de marketing para promover o alimento orgânico.

- Promover lojas de alimentos orgânicos regionais.

- Manter informação em versão impressa ou digital, bem como demonstrações do produto nas lojas e uma formação adequada do pessoal para melhorar o conhecimento dos consumidores acerca dos produtos orgânicos.

b) Abordagem centrada no processo: Este enfoque está diretamente relacionado à certificação. Ações que transmitam ao consumidor a ideia de que o processo produtivo segue regras e critérios de operação bem definidos são fundamentais aqui. Melhorias no processo, ainda que não previstas, e requisitos de normas são também elementos que podem e devem ser tornados públicos. Estampas com dados do processo e da certificação na embalagem dos produtos são recomendadas. Algumas ações são importantes para a melhoria da Qualidade de Projeto de produção dos alimentos orgânicos: desenvolver padrões claros do processo de certificação, para existir uma relação de confiança entre produtores e consumidores, e os aspectos da certificação devem ser esclarecidos ao consumidor. As normas de alimentos orgânicos que existem entre os países também poderiam ser harmonizadas, como também as empresas certificadoras deveriam ser avaliadas.

c) Abordagem centrada no produto: A rigor, alimentos orgânicos já são produtos individualizados. Além de utilizar essa característica, as empresas produtoras de alimentos orgânicos podem utilizar-se de embalagens que tipifiquem sua marca, com cores muito particulares, desenhos próprios para que se distingam das demais. Embalagens que comportem diferentes números de unidades do produto ou diferentes pesos; que agreguem vários produtos (como hortaliças, por exemplo); que contenham características que favoreçam a maior conservação ou praticidade; que sejam constituídas por materiais recicláveis; que não gerem inconvenientes ou danos aos consumidores são, também, ações inseridas nesta abordagem.

d) Abordagem centrada no valor: Um processo produtivo diferenciado dos modelos convencionais pode despertar especial interesse no consumidor. Se for entendido por ele que tal processo agrega valor ao produto (isto é, o produto incorpora características que ele considera relevantes), pode-se aceitar pagar um preço igualmente diferenciado pelo produto. Nessa linha, esta abordagem permite criar uma estratégia não para justificar, mas sim para associar o preço do alimento orgânico a valores de processo e de produto. Características efetivas do produto devem ser ressaltadas, sem que isso atente contra fatos, como no caso da falta de comprovação científica de benefícios à saúde dos alimentos orgânicos. O mesmo vale para embalagens, logística, mecanismos específicos de armazenagem, etc. Neste caso, melhorar a rastreabilidade e indicar a origem do produto nos canais de distribuição pode agregar valor para o consumidor.

e) Abordagem centrada no usuário: Esta abordagem sugere associar os produtos a especificidades de cada faixa de mercado. Isso envolve respeito à cultura local, apelo por idade ou sexo, facilidades de uso, rapidez de preparo, enfim, elementos que sejam favoráveis ao consumidor. É nesta abordagem que a Qualidade de Projeto melhor se insere, até porque este enfoque, além de ser o mais amplo dos cinco, inclui os outros quatro.

Os referenciais aqui mencionados, assim como os dois aspectos discutidos anteriormente, são 
viabilizados, na prática, por ações gerenciais como as que são descritas a seguir.

\subsection{Gestão Operacional da Qualidade}

O primeiro ambiente gerencial considerado é o que trata das ações relativas ao processo produtivo. Em tal ambiente, encontra-se o próprio desenvolvimento da certificação. O conceito que serve de base para as ações aqui listadas é o de Gestão da Qualidade no Processo, que nada mais é do que o esforço de trazer a figura do consumidor para dentro da organização, ou seja, o empenho em direcionar as operações produtivas da organização para atender plenamente ao mercado (PALADINI, 2010). Assim, com tal ênfase, são ações típicas deste ambiente:

- Crescente padronização das operações produtivas (estágio intermediário à certificação).

- Para empresas que ainda não possuem, a opção pela certificação é essencial.

- Seleção de diferenciais de processo que possam permitir a individualização dos produtos no ambiente competitivo do comércio de alimentos.

- Criação de sistemas integrados que associem a Qualidade de Projeto à Qualidade de Conformação.

- Empenho para criar crescente organização interna das operações produtivas.

- Desenvolvimento de modelos de controle para a seleção, estocagem e utilização de matériasprimas.

- Fixação de padrões mínimos de qualidade em todas as fases das operações produtivas.

- Determinação de pontos de avaliação, análise e controle ao longo do processo produtivo, sobretudo para verificar se os padrões fixados estão sendo atendidos.

As seguintes ações são direcionadas para a agricultura orgânica:

- Utilizar complemento mineral natural quando necessário.

- Adubar o solo somente com adubo orgânico.

- Utilizar vegetação diariamente sobre o solo, durante a maior parte do ano.

- Demarcar as áreas limítrofes com as propriedades convencionais.

- Utilizar somente mudas e sementes de origem orgânica.

- Alimentar os animais com alimentação 100\% orgânica.

- Utilizar medicamentos naturais no caso de manejo terapêutico.

- Cobrir os pastos com forragem orgânica.

- Construir os estábulos com pelo menos $50 \%$ da superfície contínua em material impermeável.

- Limpar sempre os estábulos e arejá-los.

- Monitorar a qualidade da água.

- Reciclar a água da chuva quando possível.

- Monitorar o uso geral da água.

- Comunicar qualquer medida de emergência que ultrapasse as sugeridas pela certificadora no caso de surgimento de ataques e infestações fortes.

- Remover os produtos à base de policarbonato do solo após o uso.

- Destinar o lixo existente a locais adequados.

- Recolher e descartar de forma segura as armadilhas para a utilização de substâncias nas culturas.

- Utilizar apenas produtos à base de policarbonatos para a cobertura de proteção de estrutura, coberturas plásticas de palha, podas, redes contra insetos e embalagens de silagem.

- Não queimar os produtos à base de policarbonato na área da propriedade.

Para o processamento de alimentos orgânicos, são propostas as seguintes ações:

- Utilizar somente os aditivos e auxiliares tecnológicos pela certificadora.

- Utilizar ingredientes de origem natural e conhecida.

- Registrar as diversas etapas do processamento.

- Verificar a qualidade da matéria-prima: certificado anual de certificação; certificado de transação emitido pela certificadora para o lote, quantidade e produto em questão, nota fiscal da compra.

- Comprovar que máquinas e equipamentos estão livres de produtos não orgânicos.

- Identificar os produtos com nome, número do lote, matéria-prima utilizada e características relevantes ao longo do processamento, armazenagem e transporte.

- Reduzir o uso de material para empacotamento.

- Utilizar materiais recicláveis sempre que possível.

- Priorizar o uso de materiais biodegradáveis.

\subsection{Gestão Tática da Qualidade}

Aqui, os processos gerenciais da organização e o envolvimento dos Recursos Humanos no esforço da qualidade são considerados. Neste ambiente, as ações propostas pelo modelo são as seguintes:

- Profissionalizar a empresa, especialmente em termos do modelo gerencial.

- Criar modelos de gestão adequados à maior conexão da organização com o mercado, sobretudo no caso das microempresas (a maioria das produtoras). 
- Promover a associação de microempresas para aumentar o poder de barganha com fornecedores.

- Fixar critérios técnicos para recrutamento e seleção de pessoal.

- Treinar, atualizar, qualificar os recursos humanos.

- Definir sistemas de integração de normas, principalmente para criar modelos gerenciais consistentes.

Especificamente, as ações para a agricultura orgânica são:

- Seguir os procedimentos para a proteção e a conservação do solo.

- Seguir o procedimento determinado para a utilização do complemento mineral.

- Seguir os procedimentos indicados pela certificadora para a utilização de material orgânico da adubação adquiridos fora da fazenda.

- Adotar métodos para a rotação de culturas (consorciação, rotação, arborização, etc.).

- Seguir os procedimentos para a realização do manejo de pragas e doenças.

- Seguir os métodos e agentes permitidos na produção vegetal e na limpeza de instalações e equipamentos.

- Seguir o procedimento para o manejo dos animais.

- Documentar tudo o que é requisitado pela certificadora.

- Possuir em local acessível a todos a lista de substâncias, medicamentos, aditivos e outros insumos permitidos na produção orgânica.

- Elaborar o plano de manejo, processos e/ou mecanismos positivos capazes de controlar pragas, doenças e invasores significativos, sob circunstâncias normais de manejo.

- Solicitar uma autorização específica à certificadora para utilizar o controle térmico de invasores e os métodos físicos para pragas, doenças e manejo de invasores. do solo.

- Seguir o critério de distanciamento da propriedade certificada para evitar o risco do potencial

- Seguir as regras para a utilização de sementes e mudas.

Para o processamento do alimento orgânico, as seguintes ações devem ser seguidas:

- Não utilizar métodos ou substâncias para reconstruir propriedades que tenham sido perdidas durante a transformação e/ou armazenagem do produto.

- Utilizar os métodos de processamento permitidos pela processadora.

- Não utilizar métodos de irradiação.

- Elaborar a descrição dos principais poluentes e contaminantes existentes nas áreas das diversas etapas do processamento.

\subsection{Gestão Estratégica da Qualidade}

A Gestão Estratégica trata da sobrevivência da organização, ou seja, da definição de meios de atuação que permita que a organização cresça e se consolide. Este ambiente enfatiza, diretamente, o cenário externo da organização, açõ̃es que refletem o futuro esperado para a empresa, o processo de diferenciação dos produtos e dos processos em relação aos concorrentes e, mais em geral, a consolidação da empresa em um mercado que se sabe competitivo. São ações típicas deste ambiente:

- Análise do mercado atual em termos demográficos de forma a promover o alimento orgânico de acordo com as características do local.

- Análise de características gerais dos mercados (poder aquisitivo, nível de educação, hábitos de consumo, modelos usuais de alimentação, etc.) já que as características sociodemográficas influenciam o consumo do alimento orgânico.

- Criação de canais mais diretos de comunicação com os consumidores, pesquisando em supermercados, feiras, lojas especializadas, etc. A proximidade física de muitas organizações produtoras de alimentos orgânicos de seus mercados consumidores, por exemplo, ajuda a estabelecer tais canais.

- Investimento no conceito de Qualidade de Projeto para produtos orgânicos, de forma a direcioná-los para faixas mais específicas de mercado, por serem alimentos individualizados.

- Empresas que atuam no mercado convencional de alimentos podem beneficiar-se da diferenciação que caracteriza os diversos tipos de produtos orgânicos e investir na diversificação, direcionando suas vendas para faixas específicas de mercado (ampliação das faixas de mercado por elas atendidas).

- Ampliação dos pontos de produção de modo a enfatizar cadeias menores de produção e, assim, facilitar o suporte logístico associado ao processo.

- Utilização da proximidade do produtor com os pontos de vendas (varejistas) para desenvolver avaliações precisas de preferências, expectativas, necessidades e desejos do mercado consumidor. $\mathrm{E}$, em seguida, canalizar tais informações para o processo produtivo no menor espaço de tempo possível, de modo a ajustar os produtos à finalidade a que se destinam.

- Ampliação da oferta de produtos com base nas vantagens que canais menores na cadeia logística podem criar, já que facilitam o acesso dos consumidores aos produtos.

- Investimento no processo de agregação de valor dos produtos. Para tanto, criar canais com o 
mercado que permitam definir o que o consumidor considera relevante no produto.

As estratégias direcionarão a empresa produtora de alimento orgânico ao atendimento do seu mercado consumidor.

\section{CONCLUSÕES}

A conclusão primeira do presente trabalho é que a certificação é útil e relevante para as empresas produtoras de alimentos orgânicos. Contudo, parece não ser suficiente para definir, para referidas empresas, um projeto estratégico de atuação consistente no mercado.

É possível que isso decorra do fato de que o modelo de certificação, em geral, prioriza a Qualidade de Conformação, sem atentar, com mais cuidado, para a Qualidade de Projeto. Assim, a proposta prática é a priorização das relações das empresas produtoras de alimentos orgânicos com as faixas de mercado às quais pretendem atender. A proposta deve considerar, obviamente, características relevantes do setor.

Assim, algumas conclusões do estudo feito são essenciais para a estruturação do modelo, entre as quais se destacam as seguintes:

(1) O setor de alimentos orgânicos brasileiro é caracterizado pela predominância de micro e pequenas empresas, especializadas, em grande parte, na produção de frutas.

(2) O principal mercado consumidor dos produtos das empresas consultadas é o Brasil, seguido, em menor escala, pela Europa.

(3) O setor tem características muito próximas a algumas constatações mais gerais. Por exemplo: observa-se que a grande parte das empresas da amostra consultada está localizada no estado de São Paulo, o que não difere da situação atual das empresas alimentícias convencionais. Isso se deve ao fato de que a maior parte da população concentra-se na região Sudeste.

(4) A certificação orgânica foi obtida por grande parte da população estudada a partir do ano 2000 , com destaque para o ano de 2010, em que oito empresas foram certificadas para o modo de produção orgânico. Observa-se também que, no período compreendido entre 2006 e 2010, 24 empresas foram certificadas, número grande quando comparado com os outros quinquênios do período de tempo analisado no presente trabalho.

(5) O maior interesse pela certificação decorre do crescimento do mercado consumidor de alimentos orgânicos.

(6) Em relação aos benefícios operacionais oriundos da certificação orgânica, as empresas apresentaram que o principal deles é a maior organização interna da empresa, o que aumenta a eficiência produtiva. Porém, esse processo não possui um direcionamento para o mercado bem caracterizado.

(7) Relativamente ao mercado, a certificação orgânica apresenta alguns benefícios indiretos e o principal deles é a expansão da parcela de mercado. Além disso, as empresas afirmaram que as vendas aumentaram após a certificação.

Deve-se observar, ainda, que a certificação não é permanente. Em intervalos de um e dois anos, um novo processo de inspeção é estabelecido. Esse aspecto reforça a necessidade de se ter os recursos humanos em processo de permanente atualização. A necessidade de investir no treinamento dos funcionários sobre o modo de produção orgânico torna-se bem evidente. Ainda que cerca de $80 \%$ das empresas pesquisadas tenham afirmado que treinam seus funcionários, não se pode minimizar a importância do citado processo.

Pela própria ênfase conferida ao modelo gerencial da organização, é importante investir na integração da certificação orgânica com outras certificações. Os resultados mostraram que $50 \%$ das empresas pesquisadas possuem outro tipo de certificação.

De modo mais amplo, constata-se que a certificação orgânica opera de uma maneira eficaz e eficiente nas empresas. Essa ação melhora a utilização dos recursos, tendo impacto indireto no aumento das vendas. Daí a necessidade de investimentos específicos em modelos gerenciais estratégicos, voltados para a consolidação da relação da empresa com as faixas de mercado a que pretendem atender.

Recomenda-se que as empresas, ao longo da cadeia de produção de alimentos orgânicos, compartilhem todo o conhecimento adquirido de forma que o produto flua de uma maneira eficiente. O pouco conhecimento dos consumidores sobre os produtos aqui em foco pode comprometer ainda mais suas percepções das variedades disponíveis. Por outro lado, pela sua ligação direta com a produção, os varejistas têm o potencial de fornecer informações sobre atividades de valor agregado no setor orgânico. Esses agentes desempenham um papel crucial na manutenção da integridade do produto desde a fazenda até o consumidor.

Os fatores necessários para o desenvolvimento de cadeias produtivas de alimentos orgânicos seguros incluem a promoção de uma coordenação horizontal e vertical, bem como a elaboração e execução de normas claras a respeito da segurança alimentar por parte do governo. 


\begin{abstract}
Inserted in the usual context of the consumer market, food products adopt innovative strategies to gain strategic positions. Moreover, the consumption products considered healthy has grown worldwide. Organic food has been increasingly demanded in the Brazilian market and other parts of the world. There is a process which can be considered as a differential for the consumption of these products, and therefore ensures its quality: the certification. This study proposes a specific guideline for producers of organic food with focus on strategic quality management. It is based on data collected from an exploratory analysis of benefits (internal and external) which Brazilian companies producing certified organic foods may have. For this purpose a survey research was carried out. The first conclusion of this study is that certification is useful and relevant to companies producing organic food. However, it seems not to be enough to present these companies with a strategic project for consistent performance in the market. This may be so because the model of certification most often gives priority to Conformation Quality without more carefully focusing on Project Quality. Thus, the proposed practice is to prioritize the relations between companies producing organic food and the market they intend to supply. The proposal must take into account relevant characteristics of the sector.
\end{abstract}

Keywords: Strategic quality management. Organic food. Market. Consumption.

\title{
REFERÊNCIAS
}

AAKER, D. A. et al. Marketing Research. New York: John Wiley and Sons, Inc, 2001.

ANDERSON, J. C.; WACHENHEIM, C. J.; LESCH, W. C. Perceptions of genetically modified and organic foods and processes. AgBioForum, Columbia, v. 9, n. 3, p. 180-194, 2006.

ARVANITOYANNIS, I. S.; KRYSTALLIS, A.; KAPIRTI, A. Health and environmental consciousness: Greek consumers' attitudes toward the organic, HACCP and ISO14000 certifications on food. Journal of International Food and Agribusiness Marketing, Philadelphia, v. 15, n. 1-2, p. 93-136, 2003.

BARUCH, Y.; HOLTOM, B. C. Survey response rate levels and trends in organizational research. Human Relations, London, v. 61, n. 8, p. 1139-1160, 2008.

BERLIN, L. et al. Purchasing foods produced on organic, small and local farms: A mixed method analysis of New England consumers. Renewable Agriculture and Food Systems, Cambridge, v. 24, n. 4, p. 267-275, 2009.

CAMPBELL, A. Is going organic the way to go? Diabetes self-management, Boulder, v. 24, n. 6, p. 75-77, 2007.

CAMPOS, C. A. O. Uma Proposta para a Integração de Sistemas de Gestão. 2006. Tese (Doutorado em Engenharia de Produção) - Universidade Federal de Pernambuco, Recife.

CHANG, H.; ZEPEDA, L. Consumer perceptions and demand for organic food in Australia: Focus group discussions. Renewable Agriculture and Food Systems, Cambridge, v. 20, n. 3, p. 155-167, 2005.

CHEN, M. Attitude toward organic foods among Taiwanese as related to health consciousness, environmental attitudes, and the mediating effects of a healthy lifestyle. British Food Journal, West Yorkshire, v. 111, n. 2, p. 165-178, 2009.

CICEK, T.; KARTALKANAT, A. Consumer dispositions towards organic food: The example of Kahramanmaras/Turkey. Journal of Animal and Veterinary Advances, Paquistão, v. 9, n. 3, p. 446451, 2010.

CRINNION, W. J. Organic foods contain higher levels of certain nutrients, lower levels of pesticides, and may provide health benefits for the consumer. Alternative Medicine Review, Napa, v. 15, n. 1, p. 4-12, 2010. 
DE CICCO, F. Sistemas Integrados de Gestão - Agregando valor aos sistemas ISO 9000. [2000]. Disponível em: <http://www.qsp.com.br>. Acesso em: 13 jun. 2013.

EVANS, J. R.; MATHUR, A. The value of online surveys. Internet Research, West Yorkshire, v. 15, n. 2, p. 195-219, 2005.

GARVIN, D. What does "Product Quality" really mean? Sloan Management Review, Cambridge, p. 25-43, Fall 1984.

GIBBON, P.; LIN, Y.; JONES, S. Revenue effects of participation in smallholder organic cocoa production in tropical Africa. DIIS Working Paper 2009:06. [2009]. Disponível em: <http://www. diis.dk>. Acesso em: 23 set. 2014.

GIL, A. C. Como elaborar projetos de pesquisa. 4. ed. São Paulo: Atlas, 2002.

GILMORE, H. L. Product conformance cost. Quality progress, USA, v. 7, n. 5, p. 16-19, June 1974.

GUTHMAN, J. Fast food/organic food: Reflexive tastes and the making of 'yuppie chow. Social and Cultural Geography, London, v. 4, n. 1, p. 45-58, 2003.

IDROGO, A. A. A. et al. Sistema Integrado de Gestão: experiência em uma empresa de esquadrias de alumínio e vidros. [2008]. Disponível em: <http://www.abepro.org.br/biblioteca/ene>. Acesso em: 12 jun. 2012.

IBGE. Instituto Brasileiro de Geografia e Estatística. As Micro e Pequenas Empresas Comerciais e de Serviços no Brasil. [2010]. Disponível em: <http://www.ibge.gov.br/home/estatistica/ economia/microempresa/>. Acesso em: 8 dez. 2014.

KOUBA, M. Quality of organic animal products. Productions Animales, Saint-Genès-Champanelle, v. 15, n. 3, p. 161-169, 2002.

LIN, L.; ZHOU, D.; MA, C. Green food industry in China: Development, problems and policies. Renewable Agriculture and Food Systems, Cambridge, v. 25, n. 1, p. 69-80, 2010.

MAGKOS, F.; ARVANITI, F.; ZAMPELAS, A. Organic food: Buying more safety or just peace of mind? A critical review of the literature. Critical reviews in food science and nutrition, Philadelphia, v. 46, n. 1, p. 23-56, 2006.

MARCONI, M. A.; LAKATOS, E. M. Fundamentos da metodologia científica. 4. ed. São Paulo: Atlas, 2001.

MARSHALL, R. S.; STANDIFIRD, S. S. Organizational resource bundles and institutional change in the U.S. organic food and agricultural certification sector. Organization and Environment, London, v. 18, n. 3, p. 265-286, 2005.

MINISTÉRIO DA AGRICULTURA, PECUÁRIA E ABASTECIMENTO (MAPA). Produção orgânica no Brasil. [2010]. Disponível em: <www.agricultura.gov.br>. Acesso em: 20 ago. 2010.

PALADINI, E. P. Gestão Estratégica da Qualidade: princípios, métodos e processos. A qualidade e as lições da crise. São Paulo: Atlas, 2010.

PEARSON, D.; HENRYKS, J.; JONES, H. Organic food: What we know (and do not know) about consumers. Renewable Agriculture and Food Systems, Cambridge, v. 26, n. 2, p. 171-177, 2011.

PELLEGRINI, G.; FARINELLO, F. Organic consumers and new lifestyles: An Italian country survey on consumption patterns. British Food Journal, West Yorkshire, v. 111, n. 9, p. 948-974, 2009.

POWELL, J. et al. The characteristics and motivations of online health information seekers: Crosssectional survey and qualitative interview study. Journal of Medical Internet Research, Toronto, v. 13, n. 1, 2011.

PUSSEMIER, L. et al. Chemical safety of conventionally and organically produced foodstuffs: A tentative comparison under Belgian conditions. Food Control, Oxford, v. 17, n. 1, p. 14-21, 2006. 
RAMESH, P.; SINGH, M.; SUBBA RAO, A. Organic farming: Its relevance to the Indian context. Current science, Bangalore, v. 88, n. 4, p. 561-568, 2005.

RAYNOLDS, L. T. The globalization of organic agro-food networks. World Development, v. 32, n. 5, p. 725-743, 2004.

ROSIN, C.; CAMPBELL, H. Beyond bifurcation: Examining the conventions of organic agriculture in New Zealand. Journal of Rural Studies, Reino Unido, v. 25, n. 1, p. 35-47, 2009.

ROTHERY, B. ISO 9000. São Paulo: Makron Books, 1993.

RUIZ DE MAYA, S.; LÓPEZ-LÓPEZ, I.; MUNUERA, J. L. Organic food consumption in Europe: International segmentation based on value system differences. Ecological Economics, Amsterdam, v. 70, n. 10, p. 1767-1775, 2011.

SCHONLAU, M.; FRICKER, R. D.; ELLIOTT, M. N. Conducting Research Surveys via E-Mail and the Web. Santa Monica, CA: Rand Corporation, 2001.

SIDERER, Y.; MAQUET, A.; ANKLAM, E. Need for research to support consumer confidence in the growing organic food market. Trends in Food Science and Technology, Norwich, v. 16, n. 8, p. 332-343, 2005.

TAGUCHI, G. Engenharia da qualidade em sistemas de produção. São Paulo: McGraw-Hill, 1990.

TRANTER, R. B. et al. Consumers' willingness-to-pay for organic conversion-grade food: Evidence from five EU countries. Food Policy, Oxford, v. 34, n. 3, p. 287-294, 2009.

VLÃSCEANU, L.; GRÜNBERG, L.; PÂRLEA, D. Quality Assurance and Accreditation: A Glossary of Basic Terms and Definitions. [2009]. Disponível em: <http://www.cepes.ro/publications/Default. htm>. Acesso em: 27 out. 2014.

WEBSTER, J. et al. Consumer awareness and self-reported behaviours related to salt consumption in Australia. Asia Pacific Journal of Clinical Nutrition, Melbourne, v. 19, n. 4, p. 550-554, 2010.

YAKOVLEVA, N.; FLYNN, A. Organic production: The adoption of a niche strategy by the mainstream food system. International Journal of Innovation and Sustainable Development, Geneva, v. 4, n. 1, p. 43-60, 2009.

ZHANG, F. et al. Modeling fresh organic produce consumption with scanner data: A generalized double hurdle model approach. Agribusiness, Hoboken, v. 24, n. 4, p. 510-522, 2008. 